\begin{tabular}{|c|c|}
\hline Title & $\begin{array}{l}\text { A n experimental study of menopause induced by bilateral ovariectomy and mechanistic effects of mesenchymal stromal } \\
\text { cell therapy on the parotid gland of a rat model }\end{array}$ \\
\hline Author(s) & El-naseery, Nesma Ibraheim; Elewa, Y aser Hosny A Ii; Ichii, Osamu; Kon, Y asuhiro \\
\hline Citation & $\begin{array}{l}\text { A nnals of anatomy - A natomischer anzeiger, 220, 9-20 } \\
\text { https://doi.org/10.1016/.aanat.2018.06.006 }\end{array}$ \\
\hline Issue Date & 201811 \\
\hline Doc URL & http:/hdl .handle.net/2115/76001 \\
\hline Rights & $\begin{array}{l}\text { (O) 2018. This manuscript version is made available under the CC-BY-NC-ND } 4.0 \text { license } \\
\text { http://reativecommons.org/icenses/by-nc-nd/4.0/ }\end{array}$ \\
\hline Rights(URL) & http://creativecommons.org/icenses/by-nc-nd/4.0/ \\
\hline Type & article (author version) \\
\hline File Information & A A NA T 2786R2.pdf \\
\hline
\end{tabular}

Instructions for use 


\section{An experimental study of menopause induced by \\ bilateral ovariectomy and mechanistic effects of mesenchymal stromal cell \\ therapy on the parotid gland of a rat model}

Nesma Ibraheim El-naseery $\dagger^{1}$, Yaser Hosny Ali Elewa $\dagger^{1,2 *}$, Osamu Ichii ${ }^{2}$, Yasuhiro Kon $^{2}$

1

Department of Histology and Cytology, Faculty of Veterinary Medicine, Zagazig

University, Zagazig 44519, Egypt

2

Laboratory of Anatomy, Basic Veterinary Sciences, Faculty of Veterinary Medicine, Hokkaido University, Sapporo 060-0818, Japan

$\uparrow$ Both authors contributed equally to this manuscript

*Corresponding author: Yaser Elewa, DVM, PhD,

- Laboratory of Anatomy, Basic Veterinary Sciences, Faculty of Veterinary Medicine,

Hokkaido University, Kita 18, Nishi 9, Kita-ku, Sapporo 060-0818, Japan

- Department of Histology and Cytology, Faculty of Veterinary Medicine, Zagazig University, Zagazig 44519, Egypt

Tel: 008011-706-5188 Fax: 008011-706-5189

Email: y-elewa@vetmed.hokudai.ac.jp, yaserelewa@zu.edu.eg 


\begin{abstract}
:
The current study was conducted on a menopause rat model induced by ovariectomy to assess the histological and immunohistochemical alterations in the parotid glands and to verify the efficiency of human umbilical cord derived-mesenchymal stromal cell (hUCB-MSCs) in treating this condition. Eighteen adult female rats were equally divided into three groups: sham-operated (SHAM), ovariectomized (OVX) and OVX injected with hUCB-MSCs (OVX + hUCB-MSCs). At 3 months post-ovariectomy, the salivary flow rate and size of the parotid glands were measured. The parotid glands were histologically investigated via H\&E stained sections. Furthermore, immunohistochemical analysis for human CD105, human CD34, proliferating cell nuclear antigen (PCNA), single strand DNA (ssDNA), Caspase 3, aquaporin (AQP)1, $\alpha$-Smooth Muscle Actin ( $\alpha$-SMA) and mouse CD34 were performed. The OVX group showed interstitial hemorrhage, dispersed acini and intracytoplasmic vacuoles in the acinar cells. Furthermore, immunohistochemical staining revealed a significant decrement in the number of ssDNA positive apoptotic cells, but a significant increment of PCNA positive proliferating cells, AQP1 positive blood capillaries, $\alpha$-SMA positive myoepithelial cells and endogenous CD34 positive hematopoietic progenitor cells in the OVX + hUCB-MSCs group as compared with the OVX group. These findings suggest a potential regenerative therapy of MSCs to injured parotid gland structures. However, further investigations are required to illustrate the mechanism of hUCB-MSCs mediated parotid gland regeneration.
\end{abstract}

Keywords: Parotid gland; ovariectomized; mesenchymal stromal cells; immunohistochemistry 
1 Abbreviations:

$2 \quad \alpha$-SMA: Alpha-Smooth Muscle Actin

3 AQP1: Aquaporin1

4 Er: Estrogen receptor

5 hUCB: human Umbilical Cord Blood

6 hUCB-MCs: human Umbilical Cord Blood-Derived Mesenchymal Stromal Cells

$7 \quad$ MSCs: Mesenchymal Stromal Cells

8 OVX: Ovariectomized

9 PCNA: Proliferating Cell Nuclear Antigen

10 SHAM: Sham-operated

11 ssDNA: Single Stranded DNA

12

13

14

15

16 


\section{Introduction}

18 In mammals, the saliva plays several essential roles including the protection of the oral cavity apparatus and

19 the gastrointestinal epithelium. Moreover, it facilitates tasting, mastication, swallowing, and even digestion

20 of food (Logemann et al., 2001). The parotid gland is one of the major salivary glands. Upon stimulation, it

21 secretes over 50\% of the total body saliva (Humphrey and Williamson, 2001). Salivary gland hypofunction is

22 frequently observed in mammals and manifested by xerostomia (dry mouth) that leads to functional oral

23 disorders. Xerostomia is associated with aging and many other systemic diseases (Yeh et al., 1998), and is

24 frequent among menopausal females (Frutos et al., 2002). Additionally, it is frequently observed after

25 radiotherapy (Jeong et al., 2013) and as a side effect of certain medications (Mortazavi et al., 2014).

26 The menopause is not a unique phenomenon to only human females, but it also occurs in a number of

27 animals with longer lives, including the primate species (Walker and Herndon, 2008). Experimentally, the

28 animal model of menopause could be achieved via bilateral ovariectomy (Arafat et al., 2016). Decline of

29 estrogen (E2) levels during menopause is considered to be a major change that leads to many changes in the

30 body (Messina et al., 2013). Interestingly, Rahnama et al. (2004) reported a correlation between the dryness

31 of the mouth and the E2 deficiency, and owed it to the presence of high-affinity E2 receptors (ER),

32 especially ER- $\beta$, in the major salivary glands of rats. Additionally, Gejima et al. (2007) detected ER- $\alpha$ in the

33 parotid gland of adult female rats. The severe affection of the parotid gland in menopausal animal models

34 has also been documented (Kusunoki et al., 2006; Mohamed et al., 2015). 

Apoptosis refers to programmed cell death that occurs in tissues to maintain homeostasis in the body. Lewis-Wambi and Jordan (2009) noticed that E2 regulates proliferation and apoptosis of many cell types. Recently, association between E2 deficiency and histological alterations induced by apoptosis in the rat's parotid gland has been noticed (Kusunoki et al.,2004). This apoptotic induction is caused mainly by free radicals (Kusunoki et al., 2006).

All therapeutic approaches to the treating of menopausal symptoms via hormonal replacement are associated with the possibility of venous thrombotic complications (Bińkowska, 2014), breast cancer, and gynecological cancers (Bregar et al., 2014). In addition, herbal therapy also has serious side effects including gastrointestinal disorder and abnormal vaginal bleeding (Xu et al., 2012), which restrict its clinical applications and encourage researchers to find safe and effective alternate therapies for the treatment of menopausal symptoms. In the past decade, tissue engineering, particularly stem/stromal cell regenerative medicine, has made significant advances in terms of restoration of the normal tissue functions. Mesenchymal stromal cells (MSCs) have been successfully isolated from bone marrow (BM) (Jiang et al.,2002), adipose tissue (Eirin et al.,2012), peripheral blood (PB) (Wan et al.,2006), and human umbilical cord blood (hUCB) (Hill et al.,2009). The unique feature of MSCs is the immunological property of positivity for CD105, CD73, and

51 CD90 while lacking the expression of CD34, CD19, CD45, and HLA-DR surface molecules (Dominici et al., 2006). The hUCB-MSCs are considered as one of the most easily available, least immunogenic and legal materials (Ding et al., 2015), having the high potential for expansion and plasticity (El Maadawi and Gabr, 
54 2011). Moreover, Doi et al. (2016) proved their safety in in vitro culture. Surprisingly, both E2 and hMSCs

55 exhibit similar antioxidant capacity and trophic effects (Valle-Prieto and Conget, 2010). In addition, Zhang

56 et al., (2012); Li et al. (2015) reported that, in high glucose culture, MSCs can differentiate into

$57 \quad$ steroidogenic cells which synthesize and secrete E2.

58 Interestingly, stromal cells have been successfully used to treat many diseases such as diabetes mellitus

59 (Soria et al., 2001), brain injury (Bang et al., 2005), cardiovascular diseases (Kawada et al., 2004; Dosi et al.,

60 2014), and several disorders associated with ovariectomy such as myocardial ischemia (Ray et al., 2008),

61 urinary incontinence (Lin et al., 2010), osteoporosis (Huang et al., 2016), and cerebellar disorders (Ahmed et

62 al., 2017). Despite the severe affection of the parotid gland in menopausal animal models and side effects of

63 its hormonal or herbal therapy, a new approach for its treatment is lacking. Therefore, the purpose of this

64 study was to evaluate histological and immunohistochemical structural alterations in the parotid gland of a

65 menopausal model, induced by abrupt E2 deficiency via ovariectomy in adult female albino rats and the

66 potential therapeutic roles of hUCB-MSCs.

67

68

69

70

71 


\section{Material and methods}

\subsection{Isolation and preparation of MSCs from hUCB}

This isolation of cells was done in the clinical chemistry and stem cell lab, in the Medical Biochemistry \&

Molecular Biology Department, Faculty of Medicine, at Zagazig University, Egypt.

77

78

\section{Collection of $h U C B$ sample}

Cord blood was obtained under complete aseptic conditions from the umbilical vein of six post-delivery full-term placentae at Zagazig University Hospital after getting informed consent from husbands and approved by the Institutional Review Board (IRB), Zagazig University (ZU-IRB \#4626). The samples were directly collected in a sterile $50 \mathrm{~mL}$ Falcon tubes containing $2 \mathrm{~mL}$ ethylene diamine tetraacetic acid (EDTA) (Lonza Bioproducts, Belgium) and $5 \mathrm{~mL}$ of phosphate buffer saline (PBS) of pH 7.2. Then, the samples were transported (maintaining temperature between $15-22^{\circ} \mathrm{C}$ ) to the clinical chemistry and stem cell lab for isolation of stromal cells.

\subsubsection{Isolation and Culture of hUCB derived MSCs}

The collected blood was diluted three times with PBS. Then, $30 \mathrm{ml}$ of diluted blood was carefully loaded on $10 \mathrm{~mL}$ of Ficoll/Paque (Lymphocyte Separation Medium 1.077, Lonza Bioproducts, Basel, Switzerland) in $50 \mathrm{~mL}$ centrifuge tubes. The centrifugation was done at $435 \mathrm{~g}$ for $30 \mathrm{~min}$ at $22^{\circ} \mathrm{C}$. After removal of the supernatant and careful aspiration of the mononuclear cells' (MNCs) layer, the MNCs were washed with PBS twice and centrifuged at $20^{\circ} \mathrm{C}$ for 10 min. Finally, the MNCs were isolated and the supernatant was 

Bio Science, Minnesota, USA) supplemented with 10\% fetal bovine serum (FBS, Lonza Bioproducts, Basel, Switzerland) and $1 \%$ penicillin-streptomycin-amphotericin B mixture as $10 \mathrm{IU} / 25 \mathrm{mg} / 100 \mathrm{ml}$ (Lonza Bioproducts, Belgium) at a concentration of $5000 \mathrm{~cm}^{-2}(0.2-0.3 \mathrm{ml} \text { media) })^{-1}$ The culture was incubated at $37^{\circ} \mathrm{C}$ in $5 \%$ humidified $\mathrm{CO} 2$ in a $\mathrm{CO} 2$ incubator (Heraeus, Germany). After overnight incubation (12-18 hours), the media were replaced in order to eliminate non-adherent cells. The media were replaced every 3 days for 12-14 days until colonies of MSC were noticed as spindle-shaped fibroblastoid cells of the first passage culture (at 80-90\% confluence) under the inverted microscope. At $37^{\circ} \mathrm{C}$ for $5 \mathrm{~min}$, colonies were released with $0.25 \%$ trypsin in $1 \mathrm{ml}$ EDTA. Immediately after trypsinization and centrifugation, subculturing was done in serum-supplemented medium and incubated in $50 \mathrm{~cm}^{2}$ tissue culture flask until adhesiveness and fusiform shape of MSCs were obtained (Bieback et al., 2004). The fourth passage of culture was used after labeling with fluorescent marker using Paul Karl Horan 26 (PKH-26) Fluorescent Cell Linker Kit (Sigma-Aldrich Chemie, Steinheim, Germany) obtained from Algomhuria Co (Mohafza st., Zagazig, El Sharqia, Egypt) as per the protocol described by Haas et al. (2000).

\subsubsection{Immunophenotypic characterization of $h U C B-M S C$ s by flow cytometry applications}

Based on stromal cell surface markers, we used monoclonal antibodies against human CD105 and CD90 (mesenchymal stromal cell surface marker) (20\% cutoff) (Zheng et al.,2013). We also used monoclonal 
incubated with either anti-human CD105 (Cat No: 323205), CD90 (Cat No: 559869), CD34 (Cat No: 4084644), or CD45 (Cat No: 349202) according to manufacturer's instructions, for $30 \mathrm{~min}$ in the dark. Cells were analyzed by FACS Scan 3 color (Becton Dickinson, Heidelberg, Germany) running Cell Quest software (BD, San Joe, USA), in the Clinical Pathology laboratories, Zagazig University.

\subsection{Animals and experimental ethics}

Eighteen female albino rats (6-months old) were obtained from the animal house, Faculty of Veterinary Medicine, Zagazig University, Egypt. The rats were housed in individual stainless-steel cages in a clean room with controlled temperature $\left(23^{\circ} \mathrm{C}\right)$ and humidity $(60 \%)$, and with a $12 \mathrm{~h}$ dark/light cycle. The animals were given a standard diet and tap water ad-libitum. The authors adhered to the Guide for the Care and Use of Laboratory Animals of Zagazig University. The experimental protocols described in this research were approved by the Institutional Review Board (IRB), Zagazig University (ZU-IRB \#4626). The rats were divided equally into three groups ( $\mathrm{n}=6$ ): sham-operated (SHAM), ovariectomized (OVX), and OVX + hUCB-MSCs. The OVX + hUCB-MSCs group received an injection of $4.5 \times 10^{6}$ hUCB-MSCs dissolved in $250 \mu \mathrm{L}$ PBS on the tail vein two months after ovariectomy for four consecutive weeks (twice in a week) (Calatrava-Ferreras et al., 2012). However, both SHAM and OVX groups were injected with vehicle (PBS) only.

\subsection{Ovariectomy procedure}

The ovariectomy was performed by method described by Huang et al. (2016) under complete aseptic conditions ten days after acclimatization of rats. Briefly, all rats were anesthetized by intraperitoneal 
injection of $1 \% \mathrm{Na}$ pentobarbital. After the onset of anesthesia, clipping and shaving the skin was done, then

130

131

132

133

134

135

136

137

138

139

140

141

aseptic scrubbing with alcohol and povidone iodine. A short dorsal midline skin incision was made halfway between the caudal edge of the rib cage and the base of the tail bilaterally with a surgical blade (No. 11).

Opening the muscles and peritoneal cavity, the adipose tissue was retracted until the ovaries were identified which were then excised after ligation of their blood supply using 3-0 vicryl. At the end of the surgical procedures, the peritoneum and abdominal muscles were closed using 3-0 vicryl and the skin suture was done with 2-0 nylon. After the surgery, rats were allowed to live in normal environment. They were given ampicillin (4000 IU/kg, intraperitoneal) for 3 days. The rats were subcutaneously given non-steroidal anti-inflammatory drug meloxicam $(0.2 \mathrm{mg} / \mathrm{kg})$ once daily for 3 successive days. The wound dressing was applied every day for a week to prevent the risk of infection. For SHAM group, both ovaries were exposed and only mobilized.

\subsection{Salivary flow rate}

Under the effect of anesthesia (intramuscular injection of a mixture of ketamine $\mathrm{Hcl}(50 \mathrm{mg} / \mathrm{kg}$ ) and xylazine $\mathrm{Hcl}(5 \mathrm{mg} / \mathrm{kg}))$, saliva was collected from all rats two to three minutes after pilocarpine was injected subcutaneously. Saliva was flowed freely into a sterile glass pipettes for a period of $30 \mathrm{~min}$ for each rat and was then harvested. Salivary flow rate was presented as microliters per minute.

\subsection{Tissue preparation for microscopic observation}

At 3 months post-ovariectomy, rats from all experimental groups were euthanized under inhalational anesthesia. The parotid glands were dissected, weighed, and immediately fixed in $4 \%$ paraformaldehyde 
149 in paraffin. Then, $3-\mu \mathrm{m}$ thick paraffin sections were deparaffinized, rehydrated, stained with hematoxylin 150 and eosin (H\&E), and observed under light microscope, and photographed with the Amscope digital camera

151 (Bancroft and Layton, 2013).

152 For the detection of the PKH26-labelled hUCB-MSCs homing, 3- $\mu \mathrm{m}$ thick deparaffinized sections of all 153 groups were examined and photographed with a fluorescence microscope (Olympus BX50F4, No. 7M03285, 154 Tokyo, Japan). 2.6. Immunohistochemistry The immunohistochemical analyses for human CD105 and human CD34, proliferating cell nuclear antigen mouse-CD34 were performed to detect hUCB-MSCs homing, proliferating cells, apoptotic cells, blood capillaries, myoepithelial cells, and endogenous hematopoietic progenitor cells, respectively (Elewa et al., 2010). In brief, antigen retrieval was done with the deparaffinized sections according to each antibody (Table 1). Then sections were incubated in methanol containing $0.3 \% \mathrm{H}_{2} \mathrm{O}_{2}$ for 20 minutes at $4{ }^{\circ} \mathrm{C}$ to block the activity of endogenous peroxidase, followed by washing in distilled water, and incubation with $10 \%$ normal blocking serum for $1 \mathrm{~h}$ at room temperature (donkey serum for PCNA immunostaining and goat serum for staining of the other antigens). Then sections were incubated overnight with the specific primary antibody diluted in PBS (pH 7.2). The antibodies and working dilutions are shown in Table 1. For negative control, 
secondary antibody, specific to the primary one, for $30 \mathrm{~min}$, followed by incubation for $30 \mathrm{~min}$ with streptavidin-peroxidase conjugate. The positive reaction was visualized with 3, 3'-diaminobenzidine tetrahydrochloride (DAB)-H2O2 solution, $\mathrm{pH}$ 7.0. Finally, the sections were washed in distilled water and counterstained with Mayer's hematoxylin.

\subsection{Histoplanimetrical analysis}

The number of immunopositive PCNA, ssDNA, caspase 3, and mouse-CD34 cells were counted in immunohistochemical stained sections at $400 \mathrm{x}$ magnification. In addition, the integrated density of AQP1 and $\alpha$-SMA were evaluated using Photoshop (Adobe Systems, San Jose, Calif., USA) followed by Image J analysis software (ver. 1.32j, http://rsb.info.nih.gov/ij). Briefly, using Photoshop we converted the RGB color images into grayscale to reduce the background color. Then, using threshold, we highlighted the signal into black color with a white background and inverted the signal color from black to white and saved the images. Subsequently, we analyzed the integrated density of the white signals on the processed images using Image $\mathbf{J}$ software.

\subsection{Statistical analysis}

All statistical analysis results were expressed as mean \pm standard error (SE). The one-way ANOVA test was used to analyze the data among different groups, followed by multiple comparisons Duncan's Post-hoc test when significant differences were observed $(\mathrm{P}<0.05)$ ( $\mathrm{n}=6$ per group). 


\subsection{Characterization of hUCB-MSCs and homing of PKH26-labeled hUCB-MSCs in parotid gland}

Morphologically, MSCs culture at day 7 of isolation showed fusiform-shaped cells (Fig. 1A). The flow

cytometric analysis of the hUCB-MSCs culture revealed that the cells had a positive expression for human

CD105 (85.65\%) and human CD90 (62.33\%), while a negative expression for human CD34 (1.36\%) and

human CD45 (2.19\%) were detected (Fig. 1B). To confirm the homing of PKH26-labeled hUCB-MSCs,

3- $\mu \mathrm{m}$ thick deparaffinized sections of all groups were examined. The MSCs were detected in the parotid

gland sections of the OVX + hUCB-MSCs group ( 3 months post-ovariectomy) as red fluorescence between

for human CD105 was observed around the acini and ducts (Fig. 2C), while the human CD34 expression was

\subsection{Salivary flow rate and weight of parotid glands}

199 As shown in Table 2, both the salivary flow rate and the weight of parotid glands were significantly

200 decreased in the OVX group when compared to the SHAM group. After hUCB-MSCs injection, a significant

201 increase was observed by comparison with that of the OVX group.

\subsection{Histological observations}


Examination of H\&E stained sections revealed that the parotid gland of SHAM group was a multilobulated organ. Each lobule was formed of a closely packed serous acini and a series of duct systems. All serous acini had very narrow lumina that could hardly be seen and were lined with pyramidal acinar cells. The acinar cell cytoplasm exhibited apical acidophilia and basal basophilia with basal rounded nuclei containing prominent nucleoli. The intralobular duct system was composed of intercalated ducts and striated ducts. Both ducts were lined with cuboidal and columnar epithelial cells, respectively, with acidophilic stained cytoplasm. The striated ducts were the predominant ducts (Fig. 3A). In the OVX group, the acini were dispersed with lightly stained cytoplasm. The acinar cells lining the acini had numerous cytoplasmic vacuoles and some crescent-shaped nuclei. The striated duct had darkly stained nuclei and an ill-defined basal striation. Additionally, an interstitial hemorrhage was pronounced (Fig. 3B). An observable improvement of the parotid gland architecture was noticed in the OVX + hUCB-MSCs group with apparently normal structures of both acinar cells and striated ducts (Fig. 3C).

The immunohistochemical staining with anti-PCNA was performed to detect proliferating cells. The positive cells were observed in the acini of the three different experimental groups, as expected (Figs. 4A, B, and C), while the negative control immunostained sections of the parotid gland of the SHAM group revealed absence group (10.56 \pm 0.63$)$, compared to the SHAM group $(30.08 \pm 2.51)$, while they were considerably higher in 
Immunohistochemical staining for caspase 3 and ssDNA were performed to observe apoptotic cell populations. The caspase 3 positive apoptotic cells were observed in the interstitial cells of the three groups absence of apoptotic cells (Fig. 5D). In the OVX group, there was a significant increase in caspase 3 apoptotic cells $(11.17 \pm 0.76)$, compared to the SHAM group $(0.83 \pm 0.17)$, while the frequency of such apoptotic cells was significantly decreased in the OVX + hUCB-MSCs group $(3.11 \pm 0.44)$ compared to the OVX group (Fig. 5E). The other apoptotic cell marker was ssDNA that were mainly detected in both acinar and ductal epithelium (data not shown) of the OVX group, while they were hardly to be seen in the SHAM and OVX + hUCB-MSCs groups. The OVX group showed a significant increase in ssDNA positive cells $(101 \pm 14.18)$, compared to the SHAM group $(1.22 \pm 0.55)$. On the other hand, the number of ssDNA positive cells was much less in the OVX + hUCB-MSCs group; however, a non-significant difference was observed in the average number of the ssDNA positive cells in the OVX + hUCB-MSCs group (4.44 \pm 1.3$)$ when compared with that of the SHAM group (Fig. 5F).

The immunohistochemical staining with anti-AQP1 was performed to examine the alterations of the blood capillaries among the three different groups. The endothelial cells of blood capillaries showed positive reactions for $\mathrm{AQP} 1$ in all groups (Figs. 6A, B, and C). No positive reaction was observed in the negative control sections of the parotid gland in the SHAM group (Fig. 6D). The integrated density of AQP1 positive 
in the OVX + hUCB-MSCs group $\left(29.05 \times 10^{6} \pm 2.87\right)$, compared to the OVX group. However, there was no significant difference in the integrated density of AQP1 positivity was observed in the OVX +

244 hUCB-MSCs group compared to that observed in the SHAM group (Fig. 6E).

245 The changes in myoepithelial cell populations were investigated in different experimental groups via 246 immunohistochemical staining with anti- $\alpha$-SMA. Interestingly, the myoepithelial cell populations showed a 247 great variation among different groups. Well-developed $\alpha$-SMA positive myoepithelial cells with numerous 248 cytoplasmic processes were observed around the acini of the parotid glands of the SHAM group (Fig. 7A), 249 while the myoepithelial cells after ovariectomy showed fewer and shorter processes (Fig. 7B). In the OVX + 250 hUCB-MSCs group, the cytoplasmic processes showed moderate development (Fig. 7C). The negative 251 control sections of the parotid gland of the SHAM group showed no positive reaction (Fig. 7D). These 252 findings were confirmed by analyzing the integrated density of immunopositive cytoplasmic processes. The 253 integrated density of positive reactions showed a significant decrement in the OVX group (33.99 X $10^{6} \pm$ 254 4.48) when compared to the SHAM group $\left(141.22 \times 10^{6} \pm 11.55\right)$. However, following treatment with 255 hUCB-MSCs, a higher integrated density of positive reactions was observed in the OVX + hUCB-MSCs group $\left(95.85 \times 10^{6} \pm 5.82\right)$ compared to that of the OVX group (Fig. 7E).

257 Immunohistochemical staining using mouse CD34 antibody in the parotid gland sections of different experimental groups was performed to evaluate the endogenous hematopoietic progenitor cell populations 259 (Figs. 8A, B, and C). The negative control sections of the parotid gland of the SHAM group revealed no positive reactivity (Fig. 8D). A significant loss of CD34 positive cells was observed in the OVX group (0.33 
$261 \pm 0.21)$ as compared with the SHAM group $(12.33 \pm 1.28)$, but their expression was markedly restored in the 262 OVX + hUCB-MSCs group $(12.17 \pm 1.35)$ in which there was no significant difference compared to the 263 SHAM group (Fig. 8E).

264

265

266

267

268

269

270

271

272

273

274

275

276 


\section{Discussion}

279 During the female reproductive cycle, E2 promotes salivary glands growth and mediates changes in saliva's

280 chemical composition (Valimaa et al.,2004) owing to the presence of ER- $\beta$ (Rahnama et al.,2004) and ER- $\alpha$

281 (Gejima et al.,2007) in the parotid gland of adult female rats. Therefore, in the present study, we investigated

282 the influence of abrupt E2 deficiency on the parotid gland structure via ovariectomy of adult female albino

283 rats. Moreover, we examined the potential therapeutic roles of hUCB-MSCs on the parotid gland architecture

284 following ovariectomy.

285 Both parotid glands weight and salivary flow rate were significantly decreased in the OVX group in 286 comparison to the SHAM group, as previously reported (Abd El-Haleem et al.,2018). It was confirmed in the

present study by our observations of the glandular architecture that showed numerous intracytoplasmic

288 vacuoles in the acinar cells of rats of OVX group. Similar atrophic changes in the parotid glands were

reported in radiated rats (Jeong et al., 2013) and in rats after bilateral ovariectomy (Parlak et al., 2014, Abd

El-Haleem et al., 2018). The cellular vacuolization is considered by Myers and McGavin (2007) as an early

291 sign of cellular degeneration. Deficiency of the trophic effects of E2 (Valimaa et al., 2004) and increment in

apoptosis (Kusunoki et al. 2006) may be the causes of these structural alterations. In the present study,

ovariectomy caused a statistically significant decrement of proliferative cell populations and increment of

apoptotic cells as compared to the SHAM group. The apoptotic cells expressed positive caspase 3 in the 
et al. (2006) found caspase 3 activation in the acinar cells of both parotid and submandibular glands of gamma-irradiated mice. The caspase-3 is required for DNA fragmentation and some of the typical morphological alterations in cells during apoptosis (Jänicke et al., 1998). Therefore, the apoptotic cells were identified based on early events (activation of caspase-3, keratin 18 cleavage) or late events (nuclear condensation, DNA fragmentation) in the apoptosis pathway as reported by Krysko et al. (2008). We proposed that the interstitial apoptotic cells could be myoepithelial cells. Both apoptotic and proliferating myoepithelial cells were detected in the submandibular glands of atrophic rats via duct ligation (Takahashi et al., 2001). The results of the present study were reinforced by the observations of Limesand et al. (2006), who clarified that glandular homeostasis requires a balance in cell proliferation and apoptosis.

Interestingly, the ovarectomized rats showed impairment of acinar and ductal structures with reduction of myoepithelial cell processes, which might explain xerostomia in the menopausal human or long-lived animals.

Recently, therapeutic approaches via stromal cells have successfully been used in many disorders such as radiation-damaged rat salivary glands (Jeong et al.,2013) and damage of parotid glands in ovariectomized rats via bone marrow-MSCs (Abd El-Haleem et al.,2018). In the current work, we chose hUCB-MSCs to

311 treat the OVX-induced damage of parotid glands due to their unique biological characteristics. The 312 hUCB-MSCs are more advantageous than bone marrow-MSCs in this context since they are younger and 313 have a wider differentiation capability (Zhao et al., 2016). 
314 After hUCB-MSCs injection in this study, we observed apparently normal acinar cells and striated ducts in

315 H\&E stained sections. In addition, the increased proliferative cells and decreased apoptotic cells in the

316 immunostained sections may suggest that MSCs may act through paracrine mechanisms via anti-apoptotic

317 factors including cytokines (Takahashi et al.,2006), stanniocalcin-1, and vascular endothelial growth factor

318 (Doorn et al., 2012) to mediate tissue repair and regeneration.

319 The AQP1 is a water channel found in the endothelial cell of blood capillaries. These channels play an 320 important role in water permeability (Li et al., 1994). Therefore, decrement of AQP1 expression in our OVX 321 group denoted dysfunction of the blood capillaries that coincided with the noticeable interstitial hemorrhage.

322 These findings are in support of the previous report of Jin et al. (2012) who demonstrated that AQP1 was 323 influenced by E2 deficiency. Smith et al. (2009) added that E2 and progesterone deficiency influence the 324 balance between vasoconstriction and vasodilatation in the submandibular gland. In our study, the 325 improvement of AQP1 densities in the OVX + hUCB-MSCs group may be due to the neovascularization 326 (Takahashi et al., 2006; Lim et al., 2013) via angiogenic cytokines (Takahashi et al., 2006) and endothelial 327 cell-derived clusterin molecules (Mishima et al., 2012) secreted by h-MSCs. Jin et al. (2012) confirmed that 328 the AQP1 play an important role in regulating body electrolyte balance and fluid secretion. In 2016, Teos et 329 al. and Delporte et al. demonstrated that AQP1 has a definite role in saliva secretion that was proved via 330 increase in saliva secretion after an intraductal injection of human AQP1 incorporated with adenovirus.

331 Our study used integrated density of $\alpha$ SMA-positive area on immunostained sections as an index of the 332 changes in myoepithelial cell populations. These densities were significantly decreased in the OVX group 
whereas they significantly increased after hUCB-MSCs treatment. This obvious myoepithelial loss clarifies its role in glandular hypofunction associated with ovariectomy, as previously reported by Safayi et al. (2012).

The most interesting finding is the presence of endogenous $\mathrm{CD} 34^{+}$hematopoietic progenitor cells around acini and ducts in the parotid glands of SHAM group. $\mathrm{CD}^{+} 4^{+}$is a cell surface marker of hematopoietic stem/stromal cells and hematopoietic progenitor cells (Sidney et al., 2014). These cells are identified as side population (SP) cells (Mishima et al., 2012). Our findings revealed the ovariectomy-induced depletion of endogenous $\mathrm{CD} 4^{+}$hematopoietic progenitor cells via apoptosis. Such findings are similar to that produced by irradiation that leads to the damage of self-renewal property of hematopoietic stromal cell in mononuclear cells isolated from bone marrow of mice (Wang et al., 2006). In our study, the mechanism of CD34 hematopoietic progenitor cells recovery may be via angiocrine (Kobayashi et al., 2010) and pleiotrophin (Himburg et al., 2010) growth factors that were secreted from recovered endothelial cells. Sidney et al. (2014) reported that the regenerative functions of endogenous stromal cells occur by providing molecular signals to the proliferating immature epithelial cells in the forms of basement membrane proteins, extracellular matrix, matrix metalloproteinases/proteases, and growth factors. Further investigations are required for further elucidation of the mechanism of hUCB-MSCs mediated parotid gland regeneration.

In summary, our results suggest that the bilateral ovariectomy could affect the parotid gland structure due to destruction of endothelial cells, and apoptosis of acinar and ductal cells. Interestingly, we revealed that most of the structural injuries of the parotid gland were improved by hUCB-MSCs therapy. Such improvement in 
352 mechanisms by MSCs might be via endothelial cells recovery and endogenous CD34 ${ }^{+}$hematopoietic 353 progenitor cells rescue. Apoptosis inhibition and proliferation enhancement mechanisms of acinar and ductal 354 cells with myoepithelial cells recovery could also be responsible. Therefore, hUCB-MSCs therapy might be 355 a good alternative to treat parotid gland destruction, especially in menopausal cases, to evade the health risks 356 of hormonal therapy.

\section{FUNDING}

358 This research was supported in part by funding from the Japan Society for the Promotion of 359 Science (JSPS) KAKENHI Grant Numbers 17K15388 and by the Hokkaido University Tenure 360 Track Program. 


\section{References}

Abd El-Haleem, M.R., Selim, A.O., Attia, G.M., 2018. Bone marrow-derived mesenchymal stem cells ameliorate parotid injury in ovariectomized rats. Cytotherapy. 20(2), 204-217.

Ahmed, S.M., Abdelrahman, S.A., Shalaby, S.M., 2017. Therapeutic Potential of Mesenchymal Stem Cells vs. Estradiol Benzoate or Avosoya on the Cerebellar Cortex of Ovariectomized Adult Albino Rats.

J. Cytol. Histol.8(1),1000444.

Arafat, E.A., Ghoneim, F.M., Khalaf, H.A., Elsamanoudy, A.Z., 2016. Anti-senescence role of

coenzyme Q10 and $17 \beta$-estradiol on submandibular gland of ovariectomized rats: histological, 380 immunohistological and molecular studies. Int. J. Clin. Exp. Pathol. 9(11),10853-10870. Elsevier, Philadelphia, pp.172-214. 

stem cells from umbilical cord blood. Stem Cells. 22, 625-634.

Bregar, A., Taylor, K., Stuckey, A., 2014. Hormone therapy in survivors of gynecological and breast cancer. The Obstetrician \& Gynaecologist. 16, 251-258. Intravenous Administration of Human Umbilical Cord Blood Stem Cells in 3-Acetylpyridine-Lesioned Rats. Stem Cells Int. 2012, 135187.

Delporte, C., Bryla, A., Perret, J., 2016. Aquaporins in Salivary Glands: From Basic Research to

Ding, D.C., Chang, Y.H., Shyu, W.C., Lin, S.Z., 2015. Human umbilical cord mesenchymal stem cells: a new era for stem cell therapy. Cell Transplant. 24(3), 339-347. Doi, H., Kitajima, Y., Luo, L., Yan, C., Tateishi, S., Ono, Y., Urata, Y., Goto, S., Mori, R., Masuzaki, H., Shimokawa, I., Hirano, A., Li, T.S., 2016. Potency of umbilical cord blood-and Wharton's jelly-derived mesenchymal stem cells for scarless wound healing. Sci. Rep. 6, 18844. 

315-317.

Doorn, J., Moll, G., Le Blanc, K., van Blitterswijk, C., de Boer, J., 2012. Therapeutic applications of mesenchymal stromal cells: paracrine effects and potential improvements. Tissue Eng Part B Rev. $18(2), 101-115$.

Dosi, R., Bhatt, N., Shah, P., Patell, R., 2014. Cardiovascular disease and menopause. J. Clin. Diagn. Res.

Eirin Zhu, X.Y., Krier, J.D., Tang, H., Jordan, K.L., Grande, J.P., Lerman, A., Textor, S.C., Lerman, L.O., 2012. Adipose tissue-derived mesenchymal stem cells improve revascularization outcomes to $8(2), 62-64$. restore renal function in swine atherosclerotic renal artery stenosis. Stem Cells. 30(5), 1030-1041.

Elewa, Y.H., Bareedy, M.H., Abuel-Atta, A.A., Ichii, O., Otsuka, S., Kanazawa, T., Lee, S.H., Hashimoto, Y., Kon, Y.,2010. Cytoarchitectural differences of myoepithelial cells among goat 576-585. 

treatment in menopause. Med. Oral. 7(1), 26-30. Sakata, R., Yoshida, H., 2007. Expression of Estrogen Receptor- $\alpha$ Protein in the Rat Digestive Tract. in vivo. 21(3), 487- 492.

Haas, S.J., Bauer, P., Rolfs, A., Wree, A., 2000. Immunocytochemical characterization of in vitro

PKH26-labelled and intracerebrally transplanted neonatal cells. Acta Histochem.102, 273-280. regeneration of hematopoietic stem cells. Nat Med. 16(4), 475-482. 

Kwon, H., 2013. Human salivary gland stem cells ameliorate hyposalivation of radiation-damaged rat salivary glands. Exp. Mol. Med. 45, e58.

Jiang, Y., Jahagirdar, B.N., Reinhardt, R.L., Schwartz, R.E., Keene, C.D., Ortiz-Gonzalez, X.R., Reyes, Verfaillie, C.M., 2002. Pluripotency of mesenchymal stem cells derived from adult marrow. Nature. 418, 41-49.

Jin, P.Y., Lu, Y.C., Li, L., Han, Q.F., 2012. Coaction of CFTR and AQP1 increases permeability of peritoneal epithelial cells on estrogen-induced ovarian hyperstimulation syndrome. BMC Cell Biol.13,

Kawada, H., Fujita, J., Kinjo, K., Matsuzaki, Y., Tsuma, M., Miyatake, H., Muguruma, Y., Tsuboi, K., mesenchymal stem cells can be mobilized and differentiate into cardiomyocytes after myocardial infarction. Blood .104, 3581-3587. 
Krysko, D.V., Berghe, T.V., D’Herde, K., Vandenabeele, P., 2008. Apoptosis and necrosis: Detection, discrimination, and phagocytosis. Methods. 44, 205-521. changes after menopause in female rat parotid. Auris Nasus Larynx. 33(1), 47-51. changes of female rat parotids. Aging cell Acta Med. Kinki. Univ. 29, 27-30. stimulate and inhibit? Breast Cancer Res. 11(3), 206. Examination of rat salivary glands for the presence of the aquaporin CHIP. Pflugers. Arch. 428, $455-460$. 

transplantation of human adipose tissue-derived mesenchymal stem cells for the regeneration of irradiation-induced salivary gland damage. PloS One. 8(8), e71167.

Limesand, K.H., Schwertfeger, K.L., 2006. Anderson SM. MDM2 is required for suppression of apoptosis by activated Akt1 in salivary acinar cells. Mol. Cell. Biol. 26, 8840-8856.

Lin, G., Wang, G., Banie, L., Ning, H., Shindel, A.W., Fandel, T.M., Lue, T.F., Lin, C.S., 2010. Treatment of stress urinary incontinence with adipose tissue-derived stem cells. Cytotherapy. 12, 88-95. xerostomia on perception and performance of swallow function. Head \& neck. 23(4), 317-321.

Mishima, K., Inoue, H., Nishiyama,T., Mabuchi, Y., Amano, Y., Ide, F., Matsui, M., Yamada, H., Yamamoto, G., Tanaka, J., Yasuhara, R., Sakurai, T., Lee, M.C., Chiba „K., Sumimoto, H., Kawakami, Function of Damaged Exocrine Glands Through Clusterin. Stem cells. 30, 1925-1937.

Mohamed, D.A., Elnegris, H.M., Wahdan, R.A., 2015. Histological effect of ovariectomy and estrogen replacement on parotid gland of adult albino rat. J. Histol. Histopathol. 2, 23. 
Mortazavi, H., Baharvand, M., Movahhedian, A., Mohammadi, M., Khodadoustan, A., 2014.

Xerostomia due to systemic disease: a review of 20 conditions and mechanisms. Ann. Med. Health Sci.

Myers, R.K., McGavin, M.D., 2007. Cellular and tissue responses to injury. In McGavin M.D., Zachary, 3(6), 749-755.

Ray, R., Herring, C.M., Markel, T.A., Crisostomo, P.R., Wang, M., Weil, B., Lahm, T., Meldrum, D.R., 2008. Deleterious effects of endogenous and exogenous testosterone on mesenchymal stem cell VEGF production. Am. J. Physiol. Regul. Integr. Comp. Physiol. 294, R1498-R1503. $\beta$-oestradiol on rats' oral mucosal structure. Bull. Vet. Inst. Pulawy. 48, 329-332. cell differentiation markers in prepubertal bovine mammary gland: Effect of ovariectomy. J. Dairy. Sci. for CD34 as a Common Marker for Diverse Progenitors. Stem cells. 32, 1380-1389. 

progesterone on parasympathetic vasodilatation in the rat submandibular gland. Auton. Neurosci. $146,87-94$.

Soria, B., Skoudy, A., Martín, F., 2001. From stem cells to beta cells: new strategies in cell therapy of diabetes mellitus. Diabetologia. 44(4), 407-415. heart by protecting cardiomyocytes from ischemic injury. Am. J. Physiol. Heart. Circ. Physiol. 291(2), H886-H893.

Takahashi, S., Nakamura, S., Shinzato, K., Domon, T., Yamamoto, T., Wakita, M., 2001. Histochem. Cytochem. 49(12), 1557-1563.

Teos, L.Y., Zheng, C.Y., Liu, X., Swaim, W.D., Goldsmith, C.M., Cotrim, A.P., Baum, B.J., Ambudkar,

I.S., 2016. Adenovirus-mediated hAQP1 expression in irradiated mouse salivary glands causes recovery of saliva secretion by enhancing acinar cell volume decrease. Gene Ther. 23, 572-579. and salivary glands. J. Endocrinol. 180, 55-62. 
Walker, M.L., Herndon, J.G., 2008. Menopause in Nonhuman Primates?. Biol. Reprod. 79(3), 398-396. 610-618.

Wang, Y., Schulte, B.A., LaRue, A.C., Ogawa, M., Zhou, D., 2006. Total body irradiation selectively induces murine hematopoietic stem cell senescence. Blood. 107(1), 358-366. and Side Effects of Chinese Herbal Medicine for Menopausal Symptoms: A Critical Review. 2012, 1-19. function: a community-based study. Aging Clin Exp Res. 10(5), 421-428. 301540. 
543 Zheng, W., Liu, D., Fan, X., Powers, L., Goswami, M., Hu, Y., Lin, P., Medeiros, L. J., Wang, S. A., 544 2013. Potential Therapeutic Biomarkers in Plasma Cell Myeloma: A Flow Cytometry Study. Cytometry $545 \quad$ Part B. 84B, 222-228.

\section{Figure Legends}

555 Fig. 1 Identification of the hUCB-MSCs. A photomicrograp of the culture at day 7 of isolation 556 showing a fusiform-shaped morphology of cells (solid arrows) (A). Histograms of flow cytometric 557 analysis of the hUCB-MSCs culture, showing positive expressions for human CD105 (85.65\%) and 558 human CD90 (62.33\%) depending on 20\% cutoff, while negative expressions for human CD34 $559(1.36 \%)$ and human CD45 (2.19\%). Open histogram indicates the negative control background 560 signal; positive reactivity is displayed in shaded histogram (B).

561 Fig. 2 Immunofluorescence analysis. Immunofluorescence detection of the homing of the 562 PKH26-labelled hUCB-MSCs around the acini (solid arrows) and ducts (dashed arrows) in the 563 parotid glandular tissues of the OVX + hUCB-MSCs group (3 months post-ovariectomy) is noticed 
564 (A, B). Immunohistochemical detection of the hUCB-MSCs homing in sections of parotid glands 565 express a positive reaction with anti-human CD 105 around acini (solid arrows) and duct (dashed 566 arrows) (C) but a negative reaction with anti-human CD 34 (D).

567 Fig. 3 Histomorphological features of the parotid glands. Representative histopathological 568 photomicrographs of H\&E stained parotid glandular tissues of the SHAM group (A), OVX group 569 (B), and OVX + hUCB-MSCs group (C) showing serous acini (S), intercalated ducts (white arrowheads), striated duct (SD) with a prominent basal striation (solid arrows), intracytoplasmic vacuoles (black arrowheads), crescent-shaped nucleus (dashed arrow), and interstitial space with hemorrhage $(\mathrm{Hg})$.

Fig. 4 Proliferating cell populations in the parotid glands. Immunohistochemical photomicrographs showing PCNA positive cells (arrows) in the acini of SHAM group (A), OVX group (B), and OVX + hUCB-MSCs group (C). The negative control stained section of the SHAM group in which the primary antibody is replaced by PBS (D). Bar chart showing the average number of PCNA positive cells of different groups (E). Each bar carrying different superscripts letters $(a, b$, and c) are significantly different as analyzed by the one-way ANOVA test, followed by the multiple comparisons Duncan's Post-hoc test $(\mathrm{P}<0.05) ; \mathrm{n}=6$ in each experimental group. Values $=$ mean \pm SE.

Fig. 5 Apoptotic cell populations in the parotid glands. Immunohistochemical photomicrographs showing Caspase 3 positive cells (arrows) in the interstitial tissues of SHAM group (A), OVX group (B) and OVX + hUCB-MSCs group (C). The negative control stained section of the OVX group in which the primary 
antibody is replaced by PBS (D). Bar charts showing the average number of Caspase 3 positive (E) and ssDNA positive apoptotic cells in different groups (F). Each bar carrying different superscripts letters (a, b and c) are significantly different as analyzed by the one-way ANOVA test, followed by the multiple comparisons Duncan's Post-hoc test $(\mathrm{P}<0.05) ; \mathrm{n}=6$ in each experimental group. Values $=$ mean $\pm \mathrm{SE}$.

Fig. 6 Blood capillary populations in the parotid glands. Immunohistochemical photomicrographs showing AQP1 positive blood capillaries in between the acini (arrows) and around striated ducts (arrowheads) of the SHAM group (A), OVX group (B), and OVX + hUCB-MSCs group (C). The negative control stained section of the SHAM group in which the primary antibody is replaced by PBS (D). Bar chart showing the integrated density ratio of AQP1 positive blood capillaries in different groups (E). Each bar carrying different superscripts letters ( $\mathrm{a}, \mathrm{b}$ and $\mathrm{c}$ ) are significantly different as analyzed by the one-way ANOVA test, followed mean \pm SE.

Fig. 7 Myoepithelial cell populations in the parotid glands. Immunohistochemical photomicrographs showing $\alpha$-SMA positive cells with their cytoplasmic processes around the acini (arrows) and intercalated duct (arrowhead) of SHAM group (A), OVX group (B), and OVX + hUCB-MSCs group (C). The negative control stained section of the SHAM group in which the primary antibody is replaced by PBS (D). Bar chart showing the integrated density ratio of distribution of $\alpha$-SMA positive cells in different groups (E). Each bar carrying different superscripts letters (a, b and c) are significantly different as analyzed by the one-way 
601 ANOVA test, followed by the multiple comparisons Duncan's Post-hoc test $(\mathrm{P}<0.05) ; \mathrm{n}=6$ in each 602 experimental group. Values $=$ mean $\pm \mathrm{SE}$.

603 Fig. 8 Endogenous hematopoietic progenitor cell populations in the parotid glands. Immunohistochemical 604 photomicrographs showing anti-mouse CD34 positive cells surrounding acini (arrows) and striated ducts 605 (arrowheads) of SHAM group (A), OVX group (B), and OVX + hUCB-MSCs group (C). Insets indicate 606 immunopositive reaction of hematopoietic progenitor cells that have large nucleus with little cytoplasm. The 607 negative control stained section of the SHAM group in which the primary antibody is replaced by PBS (D). 608 Bar chart showing the average number of mouse CD34 positive cells in different groups (E). Each bar 609 carrying different superscripts letters ( $a, b$ and $c$ ) are significantly different as analyzed by the one-way 610 ANOVA test, followed by the multiple comparisons Duncan's Post-hoc test $(\mathrm{P}<0.05) ; \mathrm{n}=6$ in each 611 experimental group. Values $=$ mean \pm SE. 
A

$50 \mu \mathrm{m}$
B

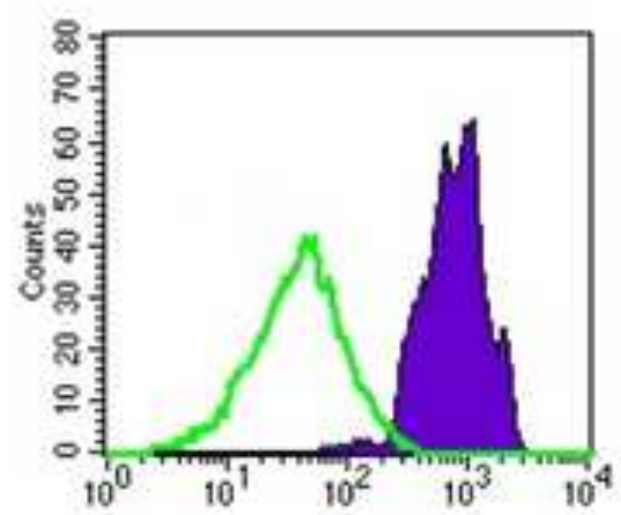

CD34

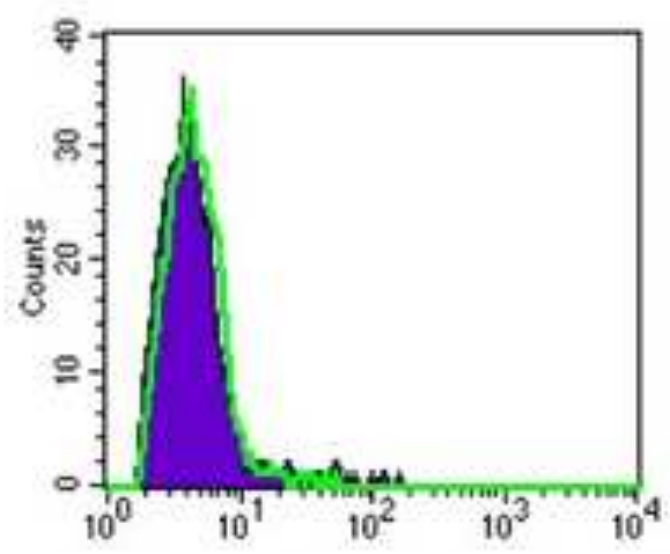

CD90

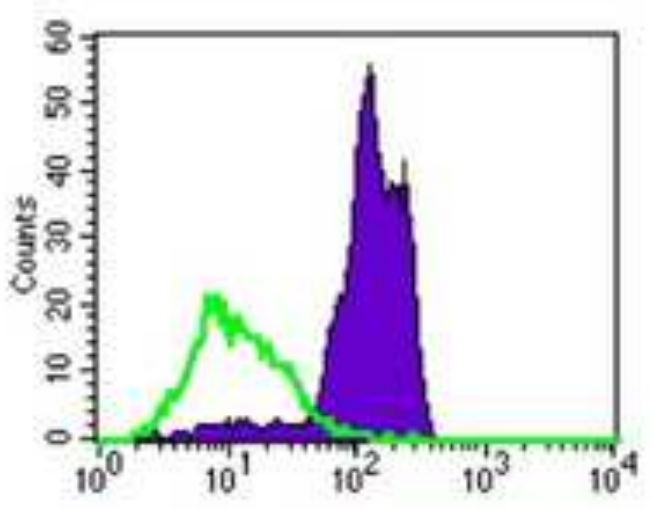

CD45

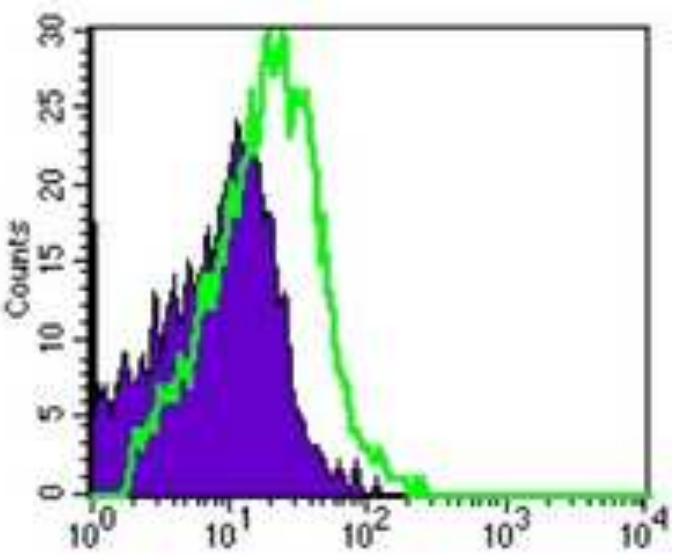


Click here to download high resolution image
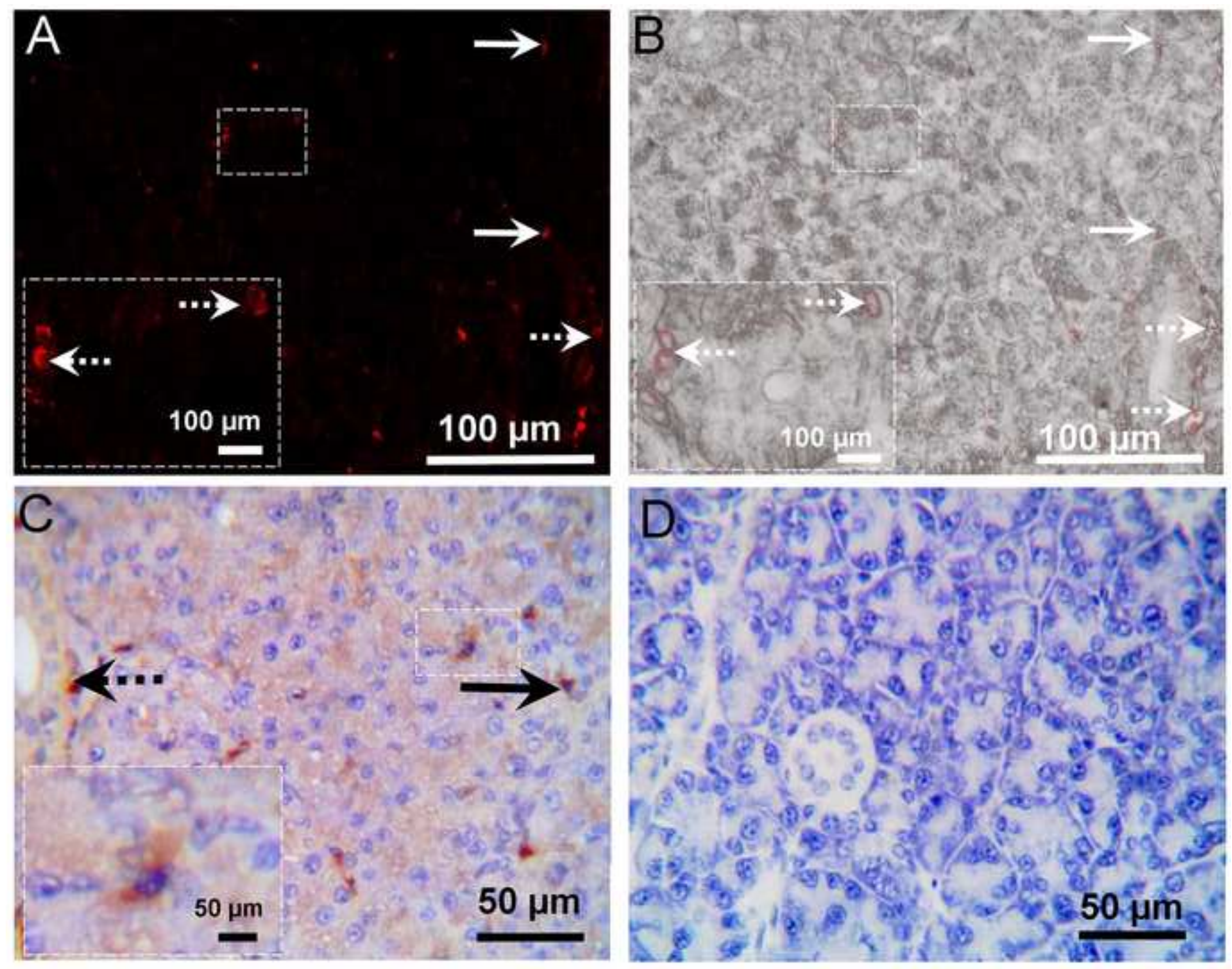
Figure

Click here to download high resolution image
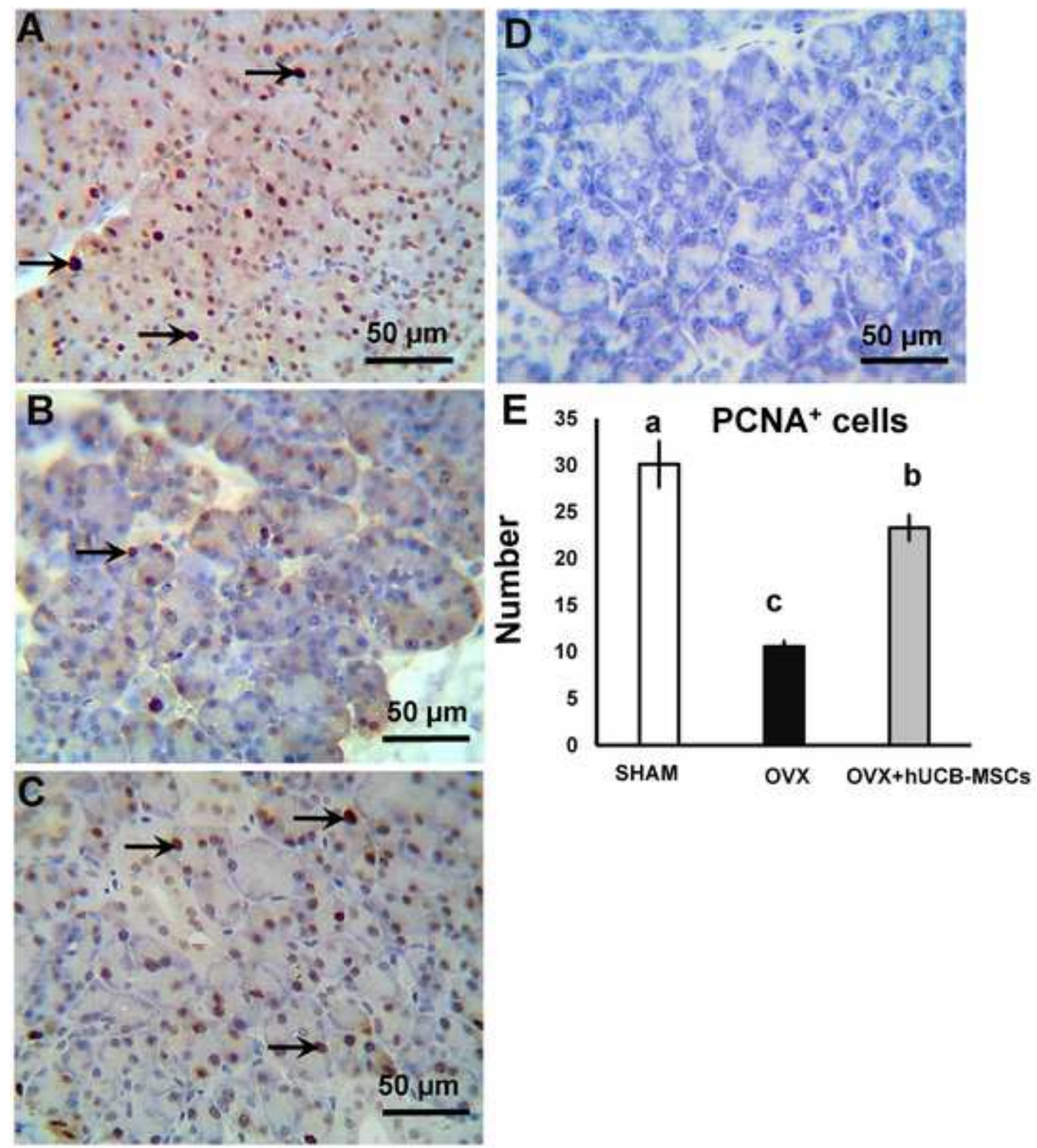

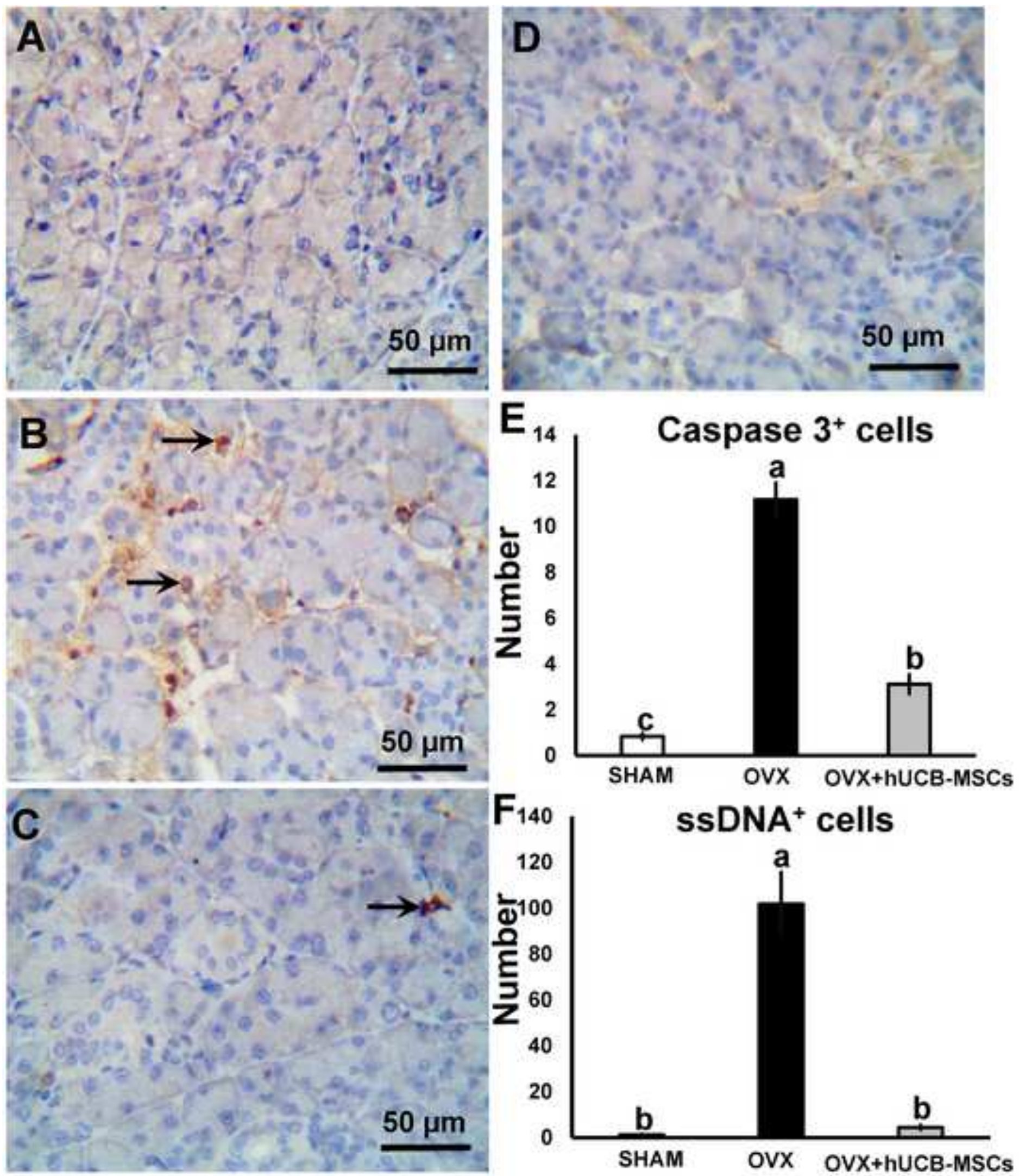
Click here to download high resolution image
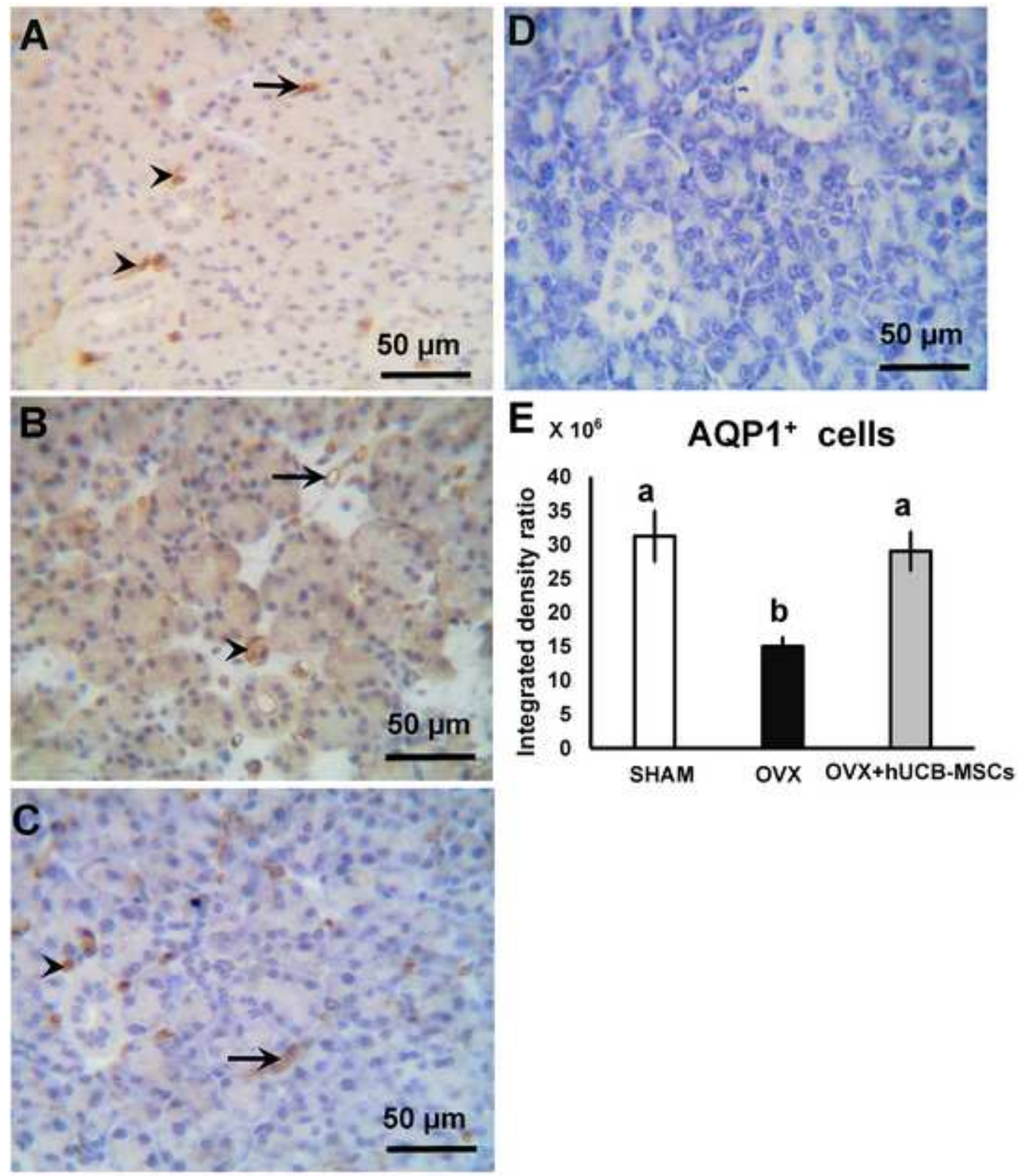
Figure

Click here to download high resolution image
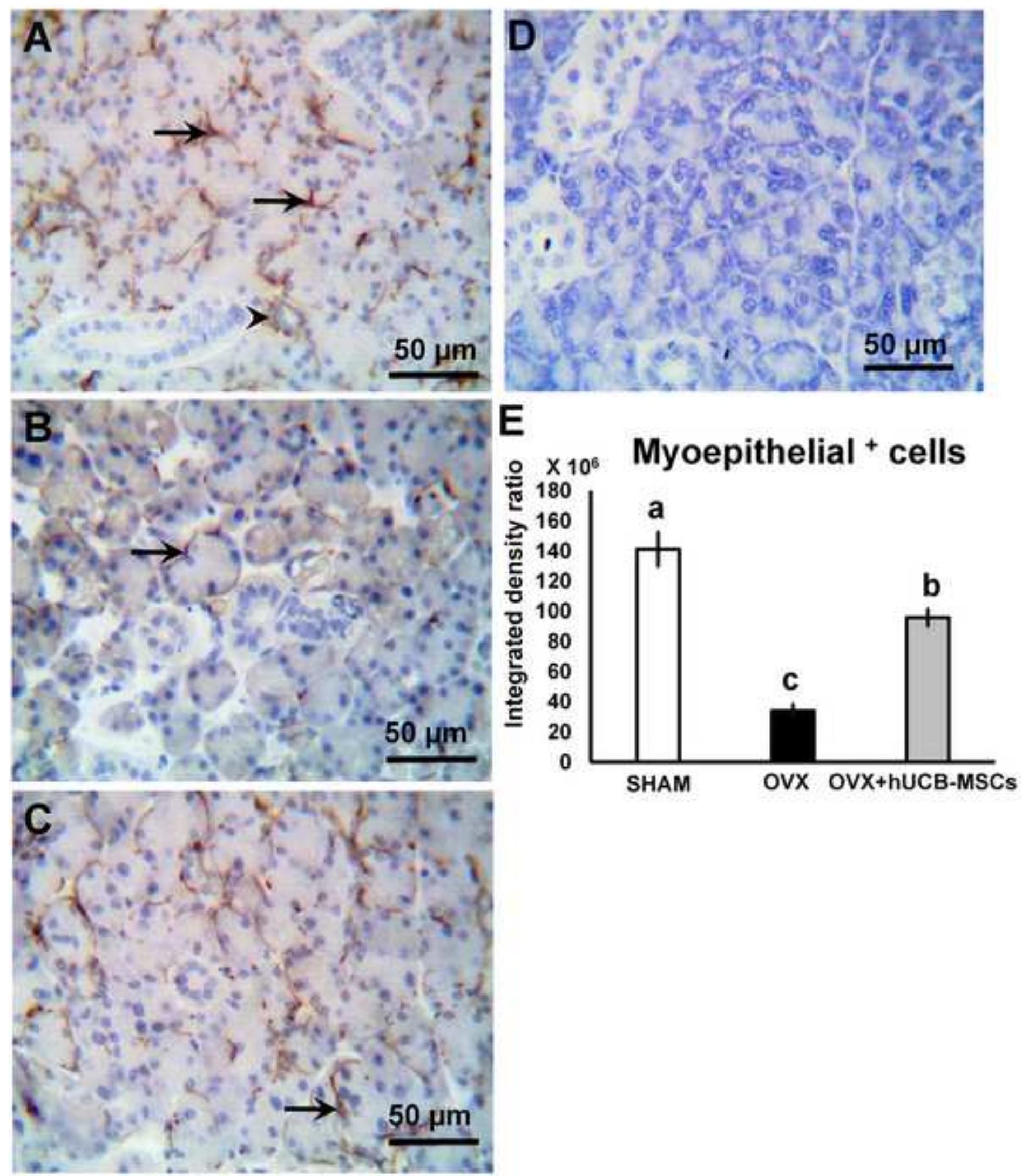
Click here to download high resolution image
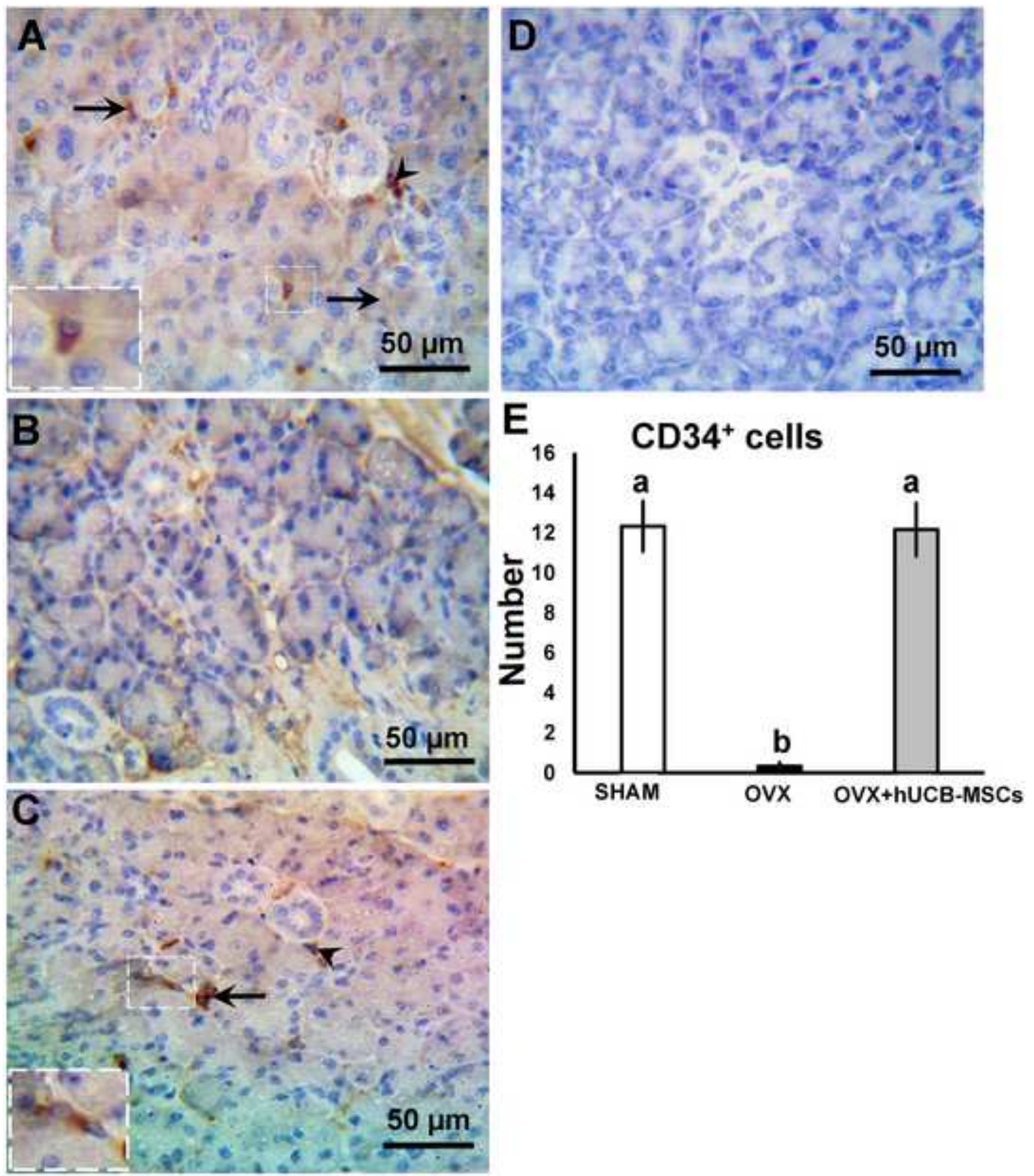
Table 1 A list of antibodies, sources, working dilutions, and antigen retrieval.

\begin{tabular}{|c|c|c|c|}
\hline Antibodies & Sources & $\begin{array}{l}\text { Dilution } \\
\text { S }\end{array}$ & Antigen retrieval, temperature, time \\
\hline $\begin{array}{l}\text { Anti-human CD105: } \\
\text { SN6h }\end{array}$ & Gennova Scientific SLc & $1: 200$ & Citrate buffer $(\mathrm{pH} 6.0), 95^{\circ} \mathrm{C}, 20 \mathrm{~min}$. \\
\hline $\begin{array}{l}\text { Anti-humanCD34: } \\
\text { QBEnd/10 }\end{array}$ & Gennova Scientific SLc & $1: 400$ & Citrate buffer ( $\mathrm{pH} 6.0), 105^{\circ} \mathrm{C}, 20 \mathrm{~min}$. \\
\hline $\begin{array}{l}\text { Monoclonal anti-goat } \\
\text { PCNA }\end{array}$ & $\begin{array}{l}\text { Santa Cruz Biochemistry, } \\
\text { (Santa Cruz, USA) }\end{array}$ & $1: 2000$ & Dako, $105^{\circ} \mathrm{C}, 20 \mathrm{~min}$. \\
\hline Anti-rabbit ssDNA & IBL - Fujioka, japan & $1: 200$ & $\begin{array}{l}\text { No antigen retrieval used, don't } \\
\text { Autoclave. }\end{array}$ \\
\hline Anti-rabbit AQP1 & Santa Cruz & $1: 50$ & $2 \mathrm{XSSC}, 105^{\circ} \mathrm{C}, 20 \mathrm{~min}$. \\
\hline Anti-rabbit $\alpha$-SMA & Abcam, Cambridge, UK & $1: 3000$ & Citrate buffer ( $\mathrm{pH} 6.0), 105^{\circ} \mathrm{C}, 20 \mathrm{~min}$. \\
\hline Anti-rabbit Caspase 3 & IMGENEX & $1: 800$ & $2 \mathrm{XSSC}, 105^{\circ} \mathrm{C}, 20 \mathrm{~min}$ \\
\hline Anti-mouse CD34 & Abcam & $1: 400$ & Citrate buffer, $105^{\circ} \mathrm{C} 20 \mathrm{~min}$. \\
\hline
\end{tabular}


Table 2 Statistical analysis of salivary flow rate and weight of parotid glands in all investigated groups.

\begin{tabular}{llll}
\hline Parameters & SHAM & OVX & OVX+hUCB-MSCs \\
\hline $\begin{array}{l}\text { Salivary flow rate } \\
(\boldsymbol{\mu l} / \mathbf{m i n})\end{array}$ & $48.08 \pm 3.07^{\mathbf{a}}$ & $10.03 \pm 1.10^{\mathbf{b}}$ & $43.85 \pm 3.56^{\mathbf{a}}$ \\
$\begin{array}{l}\text { parotid glands' weight } \\
(\mathbf{m g})\end{array}$ & $303.65 \pm 12.72^{\mathbf{a}}$ & $175.43 \pm 6.49^{\mathbf{b}}$ & $280.58 \pm 8.82^{\mathbf{a}}$ \\
\hline
\end{tabular}

Data are expressed as the mean $\pm \mathrm{SD}$.

Different superscripts indicate significant difference at $\mathrm{p}<0.05$ by one-way ANOVA followed by the multiple comparisons Duncan's Post-hoc test for analysis of difference among different groups. 